\title{
II Gincana da CPA-USS - um relato de experiência
}

\author{
Gymkhana II of CPA-USS - an experience report
}

\author{
Claudenir Pereira do Val' ${ }^{1}$, Jonas dos Santos Pacheco $^{2}$, César da Conceição Simões ${ }^{3}$, Magda \\ Vieira Barbosa ${ }^{4}$, Sileno Corrêa Brum ${ }^{5}$, Tânia Maria Machado Pinto ${ }^{6}$, Tereza Aparecida Ferreira \\ Dornelas ${ }^{7}$.
}

\section{Resumo}

Este artigo relata a experiência da Comissão Própria de Avaliação - CPA da Universidade Severino Sombra, localizada no município de Vassouras, Estado do Rio de Janeiro, ao desenvolver uma ação estratégica envolvendo o corpo discente, compreendendo a importância deste segmento no processo de avaliação institucional. Neste sentido, promoveu a II Gincana da CPA, evento realizado que teve como objetivo principal engajar o alunado no processo de avaliação interna por ela promovido. O evento contou com a participação de alunos, professores, membros da CPA e equipe gestora da instituição. Ao seu término pode-se perceber que os objetivos propostos foram atingidos em sua totalidade, pois houve o real envolvimento dos alunos na atividade proposta. Observou-se ainda uma grande integração do alunado dos diversos cursos de graduação. Ressalta-se também que o referido evento, proporcionou à comunidade acadêmica discente, a participação efetiva nos processos de tomada de decisão da equipe gestora da Instituição. Palavras-Chave: Avaliação Institucional. Educação Superior. Gincana. USS.

Como citar esse artigo. MV, Brum SC, Pinto TMM, Dornelas TAF. II Gincana da CPA-USS um relato de experiência. Revista Mosaico. 2014 Jul./Dez.; 05 (2): 19-23.

\begin{abstract}
This article reports the experience of the committee for assessment - CPA University Severino Sombra, located in the city of Vassouras, State of Rio de Janeiro, to develop a strategic action involving the student body, understanding the importance of this segment in the institutional evaluation process. In this sense, it promoted the Gymkhana II of the CPA, held event that aimed to engage the student body in the internal assessment process it has fostered. The event was attended by students, teachers, members of the CPA and management team of the institution. At its end it can be seen that the proposed objectives were achieved in full, because there was a real student involvement in the proposed activity. There was still a great integration of the students of the various undergraduate courses. It is noteworthy also that the said event, provided the student academic community, the effective participation in decision-making processes of the management of the institution staff. Keywords: Institutional Evaluation. Higher education. Gymkhana. USS.
\end{abstract}

\section{Introdução}

A avaliação é um processo contínuo e de caráter reflexivo que visa o envolvimento de todos os atores de forma integrada, buscando a melhoria contínua e primando pela evolução dos três pilares de uma instituição de educação superior: ensino, pesquisa e extensão.

Neste contexto, a Universidade Severino Sombra - USS, em sua prática de avaliação institucional, tem como premissa a consolidação de uma cultura avaliativa, por entender a necessidade de tornar os processos de avaliação interna desenvolvidos pela Comissão Própria de Avaliação - CPA e exigidos pelo Ministério da Educação e Cultura - MEC, através da Lei 10.861, de 14 de abril de 2004, instituída pelo Sistema Nacional de Avaliação da Educação Superior - SINAES, em um processo de prática consciente e contínua na comunidade acadêmica de modo geral.

Em função da importância do processo de avaliação para a instituição, no que diz respeito à busca constante de um ensino de qualidade, torna-se necessário o envolvimento do corpo discente nesta missão, dando-lhe a oportunidade de participar diretamente deste processo, pois "a prática da autoavaliação como processo permanente será instrumento de construção e/ou consolidação de uma cultura de avaliação da instituição, com a qual a comunidade interna se identifique e comprometa" (ABMES, 2004).

O trabalho que ora apresentamos é originado de um projeto piloto, realizado em 2013, intitulado "I Gincana da CPA", que teve como objetivos, o envolvimento de alunos de forma efetiva e sistemática no processo de avaliação desenvolvido pela CPA, conhecer melhor o contexto acadêmico da USS, propor soluções para pontos de fragilidade e sugestões de melhoria na

1. Coordenadora da CPA-USS; Professora Assistente II da Universidade Severino Sombra, Curso de Administração.

2. Membro da CPA-USS; Professor Assistente II da Universidade Severino Sombra, Cursos: Engenharia Ambiental, Engenharia Elétrica, Engenharia de Produção.

3. Membro da CPA-USS; Professor Assistente II da Universidade Severino Sombra, Cursos: Engenharia Civil, Engenharia Elétrica, Engenharia de Produção.

4. Membro da CPA-USS; Professora Assistente I da Universidade Severino Sombra, Curso de Enfermagem.

5. Membro da CPA-USS; Professor Adjunto I da Universidade Severino Sombra, Curso de Odontologia.

6. Membro da CPA-USS; Professora Assistente II da Universidade Severino Sombra, Curso de Pedagogia.

7. Membro da CPA-USS; Professora Titular da Universidade Severino Sombra, Cursos: Odontologia, Engenharia Ambiental e Sanitária, Ciências Biológicas. 
instituição e nos cursos, bem como integrar os alunos dos cursos participantes do evento.

O relato desta experiência, tendo como base o projeto supracitado, é considerado relevante em função de sua abordagem, pois acreditamos que possa contribuir para profissionais da área de avaliação de outras IES, no sentido de incentivar o desenvolvimento de atividades diferenciadas na rotina de avaliação, tendo como foco o engajamento dos diversos atores institucionais nesta questão.

Neste sentido, o presente trabalho relata a experiência da CPA da USS, realizada no ano de 2014, ao desenvolver uma ação estratégica envolvendo os alunos dos diversos Cursos de Graduação ofertados pela Universidade.

\section{Histórico da Avaliação na USS}

O processo de autoavaliação na USS teve início em 1998, com a constituição da Coordenadoria de Avaliação Institucional, de acordo com a Portaria $n^{\circ}$ 01/98 da Reitoria, que realizou a primeira avaliação institucional, através de um caderno único, distribuído aos discentes com a finalidade de avaliar o corpo docente. Inicialmente o processo era realizado manualmente, dois anos depois, passou a ser informatizado com a implantação do Sistema de Avaliação Acadêmica - SisAval. A partir de então, alunos, professores e funcionários passaram a realizar as avaliações através de um método informatizado. A implementação desta ferramenta, tornou o processo de avaliação mais confiável e rápido. A tabulação dos dados passou a ser realizada com mais agilidade e a emissão dos relatórios da avaliação repassados aos gestores com menor espaço de tempo, tornando o feedback mais eficaz. Com base nesses relatórios, os planos de ação eram formulados, tendo como referência as fragilidades e sugestões apontadas e as providências a respeito tomadas. $\mathrm{O}$ processo de avaliação se manteve nesses moldes até 2003, passando por diversas adaptações e melhorias contínuas.

Conforme citado anteriormente, a prática de avaliação institucional interna na USS já existia. Com a Lei do SINAES (BRASIL, 2004), o processo de avaliação interna passou a ser realizado pela CPA, que fora constituída a partir de então, juntamente com a Coordenadoria de Avaliação Institucional, tendo como parâmetro as diretrizes da lei supracitada, em seu Art. 11:

Cada instituição de ensino superior, pública ou privada, constituirá Comissão Própria de Avaliação - CPA, no prazo de 60 (sessenta) dias, a contar da publicação desta Lei, com as atribuições de condução dos processos deavaliaçãointernos da instituição, de sistematização e de prestação das informações solicitadas pelo INEP [...] (LEI N 10.861/2004 - SINAES).
A CPA da USS, através de seu regulamento, é designada pelo Reitor por meio de portaria, em cumprimento à lei do SINAES. Vale ressaltar, que mesmo vinculada à Reitoria, não tem caráter de subordinação ao setor, tendo atuação autônoma.

Atualmente, os representantes são no total de vinte e sete membros, sendo a coordenação e representações em quatro segmentos: corpo docente, corpo discente, funcionários técnico-administrativos e sociedade civil organizada. Destes segmentos, cadaum tem a composição de seis membros, com exceção do segmento discente que é composto por oito representações, inclusive alunos integrantes de diretórios e centros acadêmicos. Tal atitude demonstra a preocupação da CPA em valorizar o alunado, proporcionando ao mesmo a oportunidade de participar direta e efetivamente dos processos de avaliação interna. O mandato é por um período de um ano, podendo ser reconduzido quantas vezes a coordenação da CPA achar conveniente para a Instituição. A seleção para novos membros, tanto de aluno quanto professor, ocorre por indicação pelo reitor, quando é analisado o perfil do proponente, por ter se destacado em atividades de caráter acadêmico, o que assegura a representação de cada área. Os membros representantes dos funcionários são indicados pelo presidente da mantenedora da USS, por terem se destacado nas atividades de seu segmento, o que assegura a representação das diferentes áreas do conhecimento. O membro da sociedade civil organizada será indicado pelo dirigente máximo da Instituição, mediante comprovada atuação que se volte à promoção de atividades sociais, educacionais e culturais na comunidade.

Uma das atribuições da CPA é a condução, sistematização e prestação das informações solicitadas pelo Instituto Nacional de Estudos e Pesquisas Educacionais Anísio Teixeira - INEP, referentes aos processos de avaliação interna da instituição. Setor de relevância na avaliação institucional e de cursos, obtendo pontuação específica no instrumental de avaliação oficial do MEC.

Os resultados da coletânea de avaliações realizadas através deste setor são apresentados mediante relatórios quantitativos, que são objeto de análise e fundamentam a elaboração de um relatório qualitativo, segundo as características de cada dimensão sob estudo.

A CPA elabora, a cada semestre, relatórios referentes às avaliações de todos os cursos oferecidos pela USS, e, anualmente, um relatório referente à avaliação institucional. No primeiro e segundo semestres, é realizada a avaliação dos cursos de graduação, quando participam aluno e professor. As dimensões avaliadas são: aluno avalia corpo docente, curso e coordenação do curso; professor avalia curso (inclusive coordenação) e corpo discente. Oinstrumento de coletaé um questionário com perguntas fechadas, onde o respondente atribui 
um conceito de 1 a 5 , sendo 1 insuficiente, 2 fraco, 3 regular, 4 bom e 5 ótimo; há ainda a opção NR (não sei responder ou não se aplica). No segundo semestre, além da avaliação de cursos, citada acima, ocorre também a avaliação institucional, que tem como participantes alunos, professores e funcionários. No tocante à avaliação da instituição pelo aluno e professor, as dimensões avaliadas são: Ensino, Pesquisa e Extensão, Comunicação / Informação, Ambiente e Infraestrutura, Biblioteca, Organização e Objetivos Institucionais. Na avaliação dos funcionários, são as seguintes dimensões avaliadas: $O$ ambiente e condições de trabalho na Instituição, a Organização e Objetivos Institucionais, a Comunicação / Informação. Os relatórios da avaliação estão disponíveis para consulta na CPA e disponíveis no sítio eletrônico da IES. Encaminhados à CPA, os relatórios fornecem subsídios ao trabalho da Comissão e para os coordenadores de cursos, pró-reitorias e outras áreas da USS. Os resultados da avaliação servem para evidenciar pontos fortes e fracos da instituição e dos cursos e para sinalizar possíveis fragilidades e problemas que devem ser alvo de ações de melhoria. Tais informações são repassadas aos setores pertinentes incluindo a Reitoria da IES para conhecimento e análise, e posterior formulação do plano de melhorias das questões levantadas.

Neste sentido, Fonseca (2008, p. 25) diz que:

[...] na perspectiva de melhoria da qualidade das atividades institucionais, as instituições educativas e seus sujeitos não podem permanecer alheios aos processos avaliativos. É preciso conhecer os propósitos e os conceitos teóricos que permeiam os programas de avaliação, assim como seus resultados, de modo que a avaliação possa promover melhorias constantes nos processos e nos padrões estabelecidos nas instituições.

Faz parte da rotina desenvolvida por tal setor, reuniões periódicas deestudo, planejamentoe discussões, quando as decisões são tomadas em colegiado. Há ainda a avaliação das ações simples e complexas, que são registradas em livro de atas próprio e disponível aos interessados.

Nesse contexto, Sguissardi (1997, p. 3),

[...] defende a idéia de a avaliação é parte intrínseca e constituinte do complexo fenômeno de construção humana. Dada a ênfase que se atribui à função formativa e à natureza social e pública das instituições educativas, acentua a importância da avaliação qualitativa, sem diminuir o valor da avaliação quantitativa como parte integrante desse processo.

\section{Metodologia}

O presente estudo tratou de um relato de experiência, de abordagem qualitativa e descritiva, com o objetivo de descrever a utilização de uma estratégia diferenciada e inovadora, para envolver os alunos da
USS no processo de avaliação interna, desenvolvidos pela CPA e também demonstrar os resultados obtidos com a realização da referida estratégia.

Para corroborar a afirmativa acima, tomemos o trecho de Minayo (2004):

Na abordagem qualitativa, o pesquisador deve participar,
compreender e interpretar os eventos sociais de sua
pesquisa, considerando o sujeito do estudo, em determinada
condição social, pertencente a um determinado grupo
ou classe social com suas crenças, valores e significados.

A proposta da gincana foi construída a partir de reuniões e discussões com os membros da CPA-USS, durante o período de agosto e setembro de 2014.

A comissão definiu que a atividade seria desdobrada em três fases: a primeira foi a realização de reuniões com representações de alunos dos cursos de graduação, para apresentação do projeto. A partir daí, os alunos interessados em participar, formaram equipes de até quinze participantes, sendo uma equipe para cada curso. A segunda foi constituída pela apresentação de propostas de melhorias dos cursos ou a nível institucional (pela visão dos alunos) e uma ação de responsabilidade social, com doação de itens tais como alimento não perecível, material de limpeza e higiene pessoal e brinquedos, para instituições carentes. A terceira e última fase teve como proposta a realização de atividades lúdicas como: jogo de perguntas e respostas sobre o contexto da avaliação interna e da USS e tarefas relâmpago. Tanto na segunda quanto na terceira fase, as propostas apresentadas valiam ponto, sendo que na terceira fase foram computados ainda pontos sobre os percentuais de participação na Avaliação Institucional dos Cursos de Graduação envolvidos na gincana.

A campanha de sensibilização e divulgação do evento foi realizada com panfletagem, visitas às turmas, banners expostos pelo Campus, envio de e-mails aos alunos e postagens na página da CPA no Facebook.

\section{Resultados e Discussões}

O evento contou com a participação de 540 pessoas, sendo 486 alunos, 23 professores, 7 gestores e 23 membros da CPA-USS, com adesão de $80 \%$ do contingente de membros.

Do total de 23 cursos da USS, 7 cursos foram representados, sendo: Administração, Engenharia de Produção, Farmácia, Gestão Pública, Pedagogia, Psicologia e Odontologia. O evento teve, portanto, a representatividade de $30,4 \%$ do número geral de cursos.

Comparada com a primeira edição, a segunda edição da gincana teve expressivo crescimento, conforme demonstrado na Tabela 1: 
Tabela 1. Comparativo entre as duas edições da gincana edições 2013 e 2014.

\begin{tabular}{cc}
\hline I Gincana da CPA - 2013 & || Gincana da CPA - 2014 \\
\hline 2 equipes competidoras & 7 equipes competidoras \\
$\begin{array}{c}\text { Total de participantes: } 60 \\
\text { pessoas }\end{array}$ & $\begin{array}{c}\text { Total de participantes: } 540 \\
\text { pessoas }\end{array}$ \\
\hline
\end{tabular}

Fonte. Comissão Própria de Avaliação - CPA-USS

Ressaltamos que as propostas apresentadas pelas equipes na segunda fase foram encaminhadas aos gestores correspondentes para análise e retorno à comunidade acadêmica por intermédio da CPAUSS. Nesse sentido, a CPA incentiva e contribui para a consolidação da cultura de feedback do processo de avaliação na IES.

Com relação à atividade de responsabilidade social desenvolvida, foram arrecadados 1.912 itens que foram doados à instituições que desenvolvem trabalho social.

A realização do evento impactou positivamente no percentual de participação de aluno na avaliação dos cursos, conforme demonstrado no Gráfico 1.

Como podemos observar ocorreu aumento do percentual de participação de aluno na avaliação dos cursos, comparando-se o $1^{\circ}$ e $2^{\circ}$ semestres de 2014. Este fator, certamente, influenciou positivamente na participação geral discente na avaliação dos cursos, como podemos comprovar no Gráfico 2.

Gráfico 1. Participação discente na avaliação institucional dos cursos participantes da II Gincana da CPA da Universidade Severino Sombra, Vassouras, RJ.

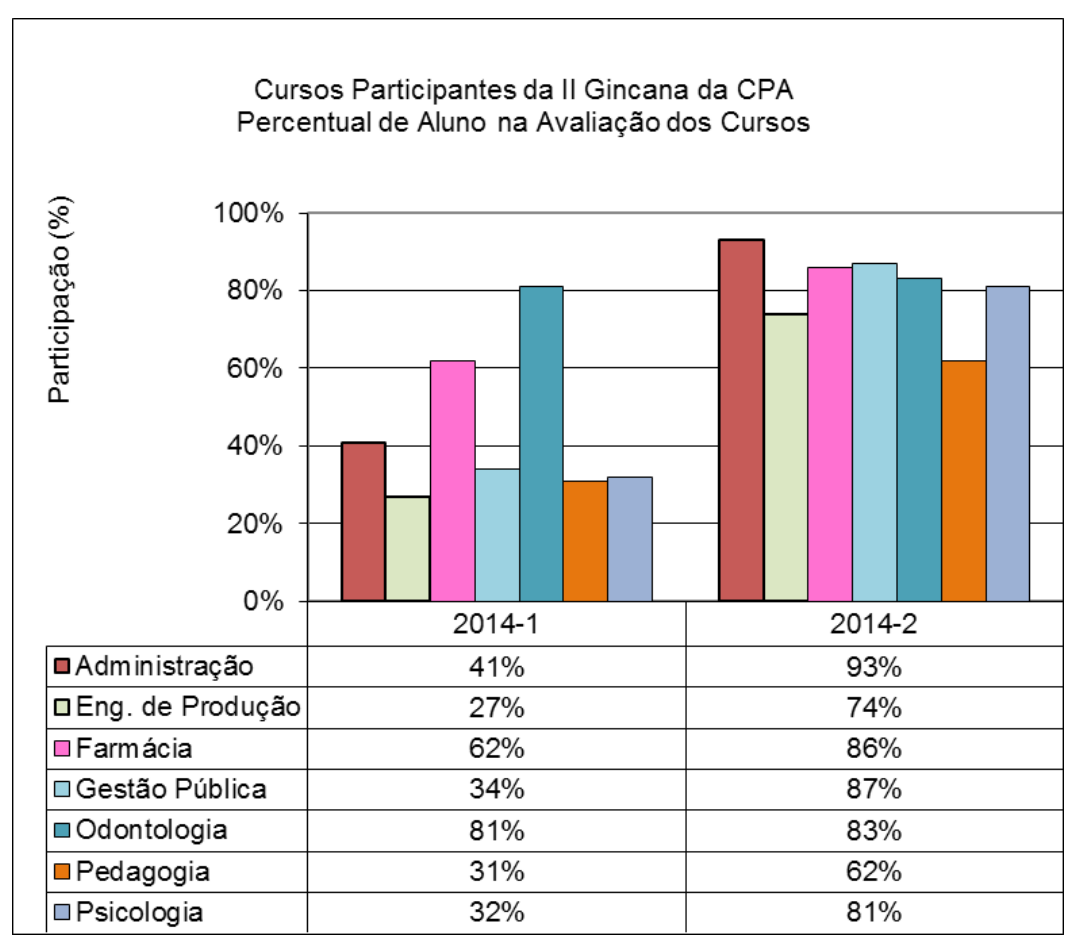

Fonte. Comissão Própria de Avaliação - CPA-USS

Gráfico 2. Participação geral discente na avaliação dos cursos da Universidade Severino Sombra, Vassouras, RJ.

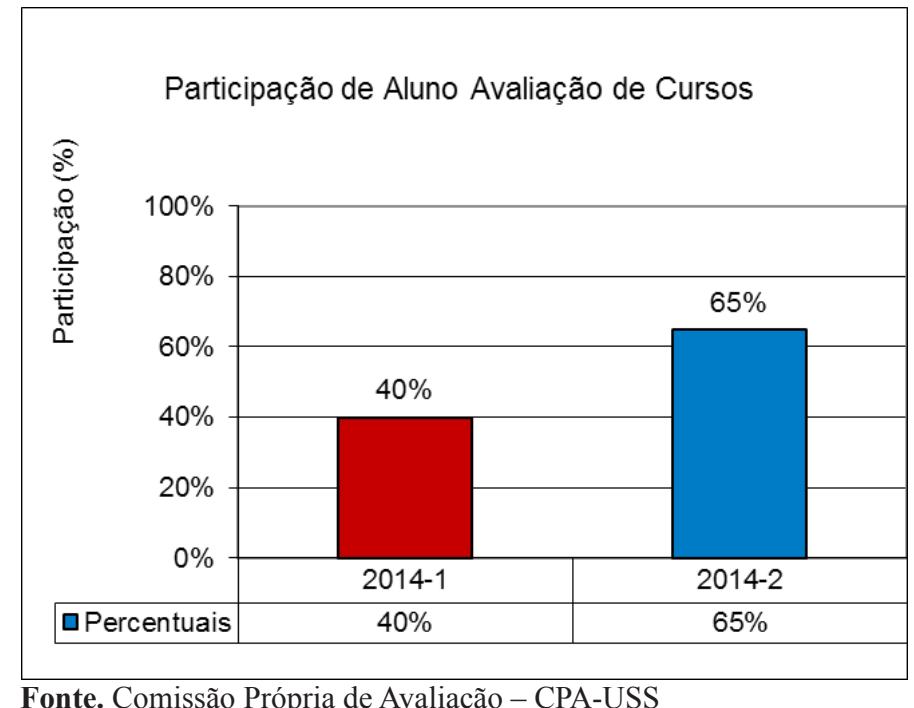


Em relação ao desempenho dos alunos durante a gincana pôde-se observar que estes estavam muito motivados, expressando alegria e empenho no desenvolvimento das tarefas, conforme depoimentos na página do Facebook da CPA: "O grupo da engenharia está formado, contamos com todos para propor melhorias aos cursos da USS. \#boraengenheiros"; "Porque quando junta a galera, a farra é garantida \#odonto\#amormaior.

Tal fato teve impacto sobre os alunos que participavam apenas como expectadores, pois estes manifestaram a vontade em competir nas próximas edições e os alunos envolvidos na execução das tarefas afirmaram que gostariam de participar novamente.

$\mathrm{O}$ evento teve um potencial de sensibilização muito grande, não só por congregar a participação dos alunos dos diferentes cursos, como também promover nos expectadores o real cumprimento da função da Comissão Própria de Avaliação, tornando o processo de avaliação realístico e concreto, onde os aspectos e etapas se articulam de forma organizada, ampliando dessa maneira, as possibilidades e aprimoramento.

Os Cursos vencedores obtiveram pontuações com pouca diferença, o Curso de Gestão Pública foi o vencedor da gincana, com 470 pontos, seguido do Curso de Farmácia, com 460 pontos, e do Curso de Administração, com 450 pontos. Portanto a diferença pequena demonstrou o grande empenho de todos os alunos participantes.

\section{Conclusão}

Diante do exposto, concluímos que o evento atingiu seus objetivos, por envolver discentes, docentes e equipe gestora, além de ter possibilitado crescimento e avanços no processo de tomadas de decisão da equipe gestora com base na discussão e apresentação direta das propostas dos alunos, através da realização da II Gincana da CPA.

Ressaltamos também que a utilização desta estratégia proporcionou a integração entre os alunos dos cursos participantes, inclusive de turnos diferentes. Outro fator em destaque é referente ao crescente interesse dos alunos em participar de tal ação em relação ao ano anterior, fato este gratificante para a equipe da CPA, visto que as metas e a credibilidade do setor estão sendo atingidas, principalmente no que tange ao envolvimento do alunado no processo avaliativo no ensino superior na IES.

Conclui-se assim, que a gincana promovida pela CPA favoreceu a aquisição de conhecimentos sobre a avaliação institucional, incluindo a relevância social através das atividades realizadas entre os cursos, onde as práticas competitivas estimulam comparações entre os desiguais com o foco pedagógico e de solidariedade humana.

\section{Referências}

ABMES - Associação Brasileira de Mantenedoras de Ensino Superior, Caderno 12, 2004.

BRASIL. Lei $\mathrm{n}^{\circ} .10 .861$, de 14 de abril de 2004. Sistema Nacional de Avaliação da Educação Superior - SINAES. Brasília, DF, 15 abr. 2004.

BRASIL. Nota Técnica INEP/DAES/CONAES n 065. 2014.

MINAYO, M. C. S. O desafio do conhecimento: pesquisa qualitativa em saúde. 8. ed. São Paulo: Hucitec, 2004.

OLIVEIRA, João Ferreira, FONSECA, Marília (org.), Eliane Gonçalves da Costa [et al]. Avaliação institucional: sinais e práticas. São Paulo: Xamã, 2008.

SGUISSARDI, Valdemar (org.). Avaliação universitária em questão: reformas do estado e da educação superior. Campinas, SP: Autores Associados, 1997.

USS. Regulamento interno da II Gincana da CPA, 2014.

Relatório de Avaliação Institucional da CPA, 2014.

https://www.facebook.com/profile.php?id=100006352428749, acessado em outubro de 2015 . 